\title{
Analysis on Safety and Risk Management in an Alteration Project of Elevators
}

\author{
Yong-nan ZHANG \\ Binhai new area tanggu Newport 2 road no. 2618, Tianjin, China
}

Keywords: Elevators Renovation, Safety, Risk Management.

\begin{abstract}
These years, economy has been developing at a fast pace, more and more elevators will be degraded. Consequently, this article through the analysis of the safety of the elevator renovation project risk and the reasons for the safety accidents, conclusion safety and risk management is based on the regulation of risk and risk control technology research of a management discipline, the risk identification, analysis, evaluation, on the basis of the risk to take effective control and properly handle, achieve the goal of security.
\end{abstract}

\section{Project Background}

These years, economy has been developing at a fast pace by $10 \%$ or so in China, where urbanization has been facilitated a lot and cities have been expanding. As a result, urban construction land has been expanded, which conflicts with limited land resources. High-rise residential buildings are solutions for mollifying this conflict. As a consequence, the number of high-rise buildings has been increasing fast. As major means of vertical transportation that run inside high-rise buildings of cities, elevators have been increasing. According to design specifications for urban buildings, elevators must be installed for residential buildings which have more than 7 floors. In addition, they are also installed for commercial buildings with 2 to 6 floors. Thus, it is clear that numerous elevators are installed in China.

As per incomplete statistics, more than 4,000,000 elevators had been installed in China by the end of 2015, and the number of elevators installed has been increasing fast by 400,000 annually. At present, China ranks Top 1 all over the world in annual total production of elevators, total number and growth of installed elevators.

Quality of elevator operations is directly related to safety of people's life and property, so safety of elevator operations has aroused great concerns of people from all walks of life. Nowadays, elevators which have been installed earlier are gradually entering mid and late stages of their service life, so they have been old. As their parts and components are worn and torn, elevators will run less and less reliably, while their mean time between failures will be shortened a lot, thus impacting everyday life of some people. As time goes by, more and more elevators will be degraded. Consequently, elevator accidents have happened frequently, greatly endangering safety of people's life and property.

With the promotion of urbanization, the growth of elevator productions and sales has declined from double digits to a single digit. Nevertheless, the ownership of elevators has increased cumulatively. The elevator industry will shoulder heavy responsibilities for normal and safe operations of elevators. The service life of elevators is limited, so it can't be maintained and prolonged unless the elevators are meticulously maintained, appropriately altered and updated. Hence, alteration projects for elevators have been increasing. Elevators are special equipment, so there are lots of safety risks in the process of elevator alterations [1].

\section{Analysis on Major Safety Risks in Alteration Projects of Elevators}

According to Classification Standards for Injuries and Casualties of Corporate Workers Altering Elevators (GB6441-1986), potential safety accidents which might happen on construction sites are classified into five categories, namely falls from height, mechanical injuries, lifting injuries, object attacks and electric shock. 


\section{Falls from Height}

Circumstances that might cause falls from height include falls from scaffolds, or entrances of caves on edges, openings of elevator shafts or pre-left holes, or falls in hoisting materials, falls occurring during ladder operations, or falls happening in demolition works (e.g. scaffolds).

After a further analysis, causes of falls from height are found to mainly include 1. operators' lack of corresponding safety knowledge, relatively weak safety awareness, no understanding about hazards or no protection against hazards (e.g. Safety belts are not fastened or not fastened in place; Helmets are not worn during work at heights or not tightly fastened); 2. Operators operate against rules and managerial personnel at all levels give illegal commands; 3. No protective measures are taken for safety on construction sites, or inadequate protective measures are available on construction sites (e.g. Scaffolds are defective); 4. Operating conditions are harsh (including harsh natural conditions or lighting, or unclosed openings or holes; and 5. inappropriate safety inspection on construction sites, safety management personnel's failure to explain safety technologies and inadequate supervision.

\section{Mechanical Injuries}

Equipment that might lead to mechanical injuries include various electric devices (e.g. polishing machines, electric welding machines, impact drills, winches, gantry cranes), different mechanical equipment (e.g. bucker loaders and hydraulic cars) and tools (e.g. screwdrivers, hammers and pliers). Causes of mechanical injuries may be divided into two categories: 1. Operators' improper operations (e.g. Operators' application of unsuitable protective measures or protective tools or improper use, tension or distraction, or wrong operations resulting from operators' clumsiness; 2 . external environment like safety risks in machine or equipment design, structures or manufacturing processes, inadequate supervision resulting from inappropriate safety inspection, non-standard operating conditions or emergent harsh climate.

\section{Lifting Injuries}

Potential causes of lifting injuries mainly include lifting slings and extrusion injuries such as fall of main hoists or guide rails.

In general, causes of lifting injuries are classified into two categories as follows. One kind of these causes include operators' illegal operations or failure to implement precautionary measures against accidents seriously, drivers' lack of skills or untimely response to emergencies. The other type of causes comprise quality defects in lifting appliances, defects in lifting slings and other accessories, inadequate field inspection and supervision, or non-conforming external construction conditions (including poor lighting, relatively heavy wind and narrow space for lifting).

\section{Object Attack}

Object attack mainly refers to attack by objects falling from a side perpendicular to the attacked during crossover operations or at the entrance of a passageway. Potential causes of object attack primarily include injuries induced by fall of parts or stones from heights, fall of discarded litters, slings or riggings. For instance, personal injuries arise from fall of foreign objects into hoistways from outside the doors owing to inadequate protection of landing doors.

Causes of object attack include failure to act in accordance with requirements or wear helmets, lack of good habits for using tools in the process of work, lack of safety signs or protective measures in discarding objects, appointment of no special personnel for hoisting materials, impossibility for properly blocking fallen objects owing to inadequate protection of flat or fine meshes.

\section{Analysis on Causes of Safety Accidents in Alteration Projects of Elevators}

Generally, there are relatively diverse and complicated risk factors impacting safety in alteration projects of elevators, including people, things, environment and management, which interact with each other and can't be easily distinguished. However, these factors can be generally divided into 
subjective and objective factors as a whole. Subjective factors are people's unsafe behavior, while objective factors include unsafe conditions and environmental factors of things[2].

\section{People's Unsafe Behaviour}

Apparently, people's unsafe behaviours refer to people's behaviours impacting safe work or operations or accidents in the process of work or operations. They are not only manifestations of risk factors, but also inducements and root causes of accidents. Workers who engage in alteration projects of elevators are exposed to many different risk factors anytime and anywhere.

Once risk factors are out of control, accidents will be inevitably caused. Concerning causes of accidents, people are the most fundamental and immediate causes of accidents. In altering elevators, all personnel are likely to make mistakes. In case of any unsafe behaviour, operators probably cause accidents. In general, the consequences of mistakes are rarely foreseeable, because mistakes result from many factors such as fatigue, bad state of mind, lack of concentration, unskilled operations of equipment, environmental impacts and excessive psychological stress. In addition, people's unsafe behaviours may result from non-compliance with requirements for external stimuli or deviation of behaviours from requirements. Furthermore, failure to thoroughly master correct methods or intentional inappropriate behaviours results in people's unsafe behaviours and unsafe factors. To sum up, people's unsafe behaviours committed in the course of operations are mainly as follows:

Fluke Mind. Workers altering elevators have fluke mind because of following factors. Firstly, empirical mistakes. For example, workers altering elevators will have psychologically weaker consciousness of risks if no accident has ever resulted from any operation against rules or no accident has happened for years. Secondly, misunderstandings. Some workers consider that accidents don't happen often, or injuries wouldn't be rather serious even if they are caused, so they are quite tolerant to their unsafe behaviours. Over a long period, the formation of unsafe behaviours contributes to operational habits of workers altering elevators and inevitably leads to the occurrence of accidents. Just as the saying goes, what if it happens.

Therefore, corrective actions must be taken from the first violation of rules and people's unsafe behaviours are strictly forbidden.

Psychological Paralysis. Psychological paralysis has several characteristics as follows. Firstly, some people perceive no risk because they get used to doing what they often do. Secondly, they don't care much about what they have done repeatedly. Thirdly, they operate as usual as they are not concerned about abnormal phenomena. Fourthly, they are irresponsible and muddle along as long as they can. Dominated by such mentality, they operate habitually as usual and act based on their past experiences, thus becoming less vigilant about risk factors and ultimately causing accidents.

Expedience. Requisite safety rules, safety precautions, and safety equipment are deemed to be obstacles to attaining goals. Such mentality for expedition and shortcut is a mental habit that workers altering elevators develop through their long-term work. For instance, some workers don't wear helmets during working at heights for the sake of convenience, or enter prohibited areas of hoisting without authorization for the purpose of saving time, or disassemble safety devices for saving troubles.

Antagonism. Under certain specific circumstances, some workers altering elevators don't behave normally but antagonistically due to their aggressiveness, curiosity, craving for knowledge, ideological prejudice and enmity. The major sign of antagonism is sticking to wrong practices instead of accepting correct and kind-hearted advices and criticism. For instance, in the event that certain worker is required to hoist equipment according to operating procedures, he might not operate in line with these procedures when he thinks that he is unskilled. A worker who is familiar with equipment performances and instructions may not operate as per what he is familiar with owing to his curiosity.

\section{Unsafe Conditions and Environmental Factors of Things}

Unsafe state of objects and environment as well as motion trajectory of unsafe environmental conditions. In case of intersecting with the motion trajectory of people's unsafe behaviours, 
accidents will happen no matter from the perspective of time or space. Hence, unsafe state of objects and environment is an immediate cause of accidents. Thus, it is direct realistic significance for preventing and eliminating accidents by correctly judging specific unsafe state of objects and environment and controlling their development [3]. In general, unsafe state of objects and environment exists in several forms as follows:

(1) Protection against Specifications, including Inappropriate Height or Strength

(2) Lack of Necessary Protective Equipment

(3) Unsafe Design of Machines and Tools

(4) Unreasonable Equipment Layout and Arrangement

(5) Poor Lighting or Intense Light

(6) Narrow Workplaces and Passageways

\section{Conclusions}

Safety risk management is a management discipline for exploring laws based on which risks take place and risk control technologies. After identifying, analyzing and evaluating risks, effective measures shall be taken to control and appropriately cope with risks for the final purpose of protecting safety. Likewise, safety risk management is helpful for preliminarily foreseeing and controlling hidden dangers, standardizing personnel's behaviours, improving production environment and preventing accidents in safe productions, thus realizing the objective of comprehensively improving enterprises' prevention of safety risks.

This elevator project will be more or less restricted in different aspects when it is implemented. In spite of relatively considerable revenues from the economic perspective and no many technology updates, the risk assessment in this paper is not quite promising because the construction team appointed for this project has no installation or commissioning experience for any similar project, whereas this elevator project is totally acceptable. From the order of precedence of risks, key causes of risks in this project are more evident. Thus, project managers only need to pay adequate attention to these causes. As a whole, results from risk assessment of this project are relatively ideal and opportunistic. Nonetheless, risks are unavoidable in implementing the project, so they can't be underestimated by managers and executors participating in the project. In addition, the practical work of this project has demonstrated conclusions of this paper. In view of the project managers' concerns about safety, no safety accident happened in this project. Nevertheless, suppliers entering into contracts for the project postponed their delivery as numerous components were imported for this project at prices which fluctuated a lot. Besides, the outsourcing team was not so familiar with the elevators used in this project that their work was delayed to certain extent. As a result, handover was postponed and penalties were fined. However, the revenues of this project are acceptable as a whole.

Above all, this elevator project can be smoothly implemented as long as safe production is guaranteed. While improving safety risk management, it is somewhat useful for increasing economic benefits and market competitiveness of construction enterprises, which is extremely important for these enterprises. In China, construction enterprises still face lots of problems in their safety risk management. In general, their management skills are relatively poor and different. Additionally, elevator projects are easily impacted by factors such as social environment, market circumstances, economic and natural conditions. Therefore, a majority of Chinese construction enterprises have really gone through an extremely long process for safety risk management by establishing and improving their safety management systems.

\section{References}

[1] Wei Ling, Construction engineering project risk management, Inner Mongolia coal economy.9 (2012) 98-99. 
[2] QiaoFa, Engineering project risk management mechanism research, Science and technology information. 8(2014) 263-264.

[3] Wang Lei, Study of communication engineering project risk management, Information and communication. 3(2014) 212-213. 